\title{
Linfoma plasmablástico anal. Reporte de dos casos
}

\author{
Anal plasmablastic lymphoma. Report of two cases \\ Cristina Grijalva-Santana,* David San Marcos-Romero, ** Billy Jiménez-Bobadilla,*** \\ Saulo Mendoza-Ramírez, ${ }^{* * * *}$ Milly Diorey Reyes-Hansen, ${ }^{* *}$ Carlos Cosme-Reyes*+
}

\author{
Palabras clave: \\ Linfoma \\ plasmablástico, \\ tumores poco
} frecuentes en el ano.

Key words: Plasmablastic lymphoma, uncommon tumors in the anus.

\footnotetext{
* Cirujano Colorrectal. Adscrito al Servicio de Cirugía Colorrectal.

** Cirujano General.

Diplomado en Fisiología Anorrectal.

*** Cirujano Colorrectal. Jefe del Departamento de Cirugía Colorrectal. Jefe del Curso de Cirugía Colorrectal.

**** Patólogo Clínico. Adscrito al Servicio de Patología.

${ }^{+}$Revisor
}

Hospital General de México. Secretaría de Salud. Ciudad de México.

Recibido: 18/04/2016 Aceptado: 06/06/2016

\section{RESUMEN}

El linfoma plasmablástico (LPB) es un tipo de linfoma de crecimiento rápido y agresivo que se considera una variante del no Hodgkin. El riesgo relativo de desarrollar este tipo de linfoma en pacientes con virus de inmunodeficiencia humana (VIH) positivos es de 80 a 110 veces mayor que en la población general. Los linfomas en sujetos VIH positivos también se han asociado fuertemente con infección por otros virus, lo que sugiere un papel importante de estos en la patogenia de los linfomas. Se identificaron dos individuos en el archivo de expedientes clínicos del Servicio de Coloproctología en el Hospital General de México con diagnóstico de LPB de la región anal. Se realizó una revisión de la historia y evolución clínica de estos dos casos, así como sus estudios de imagen; asimismo, se hizo una revisión de las laminillas complementada con reacciones de inmunohistoquímica. El LPB en el canal anal es una patología poco frecuente, con una mortalidad elevada dentro del primer año y una pobre respuesta al tratamiento con quimioterapia. Existen pocos casos reportados en la literatura mundial; nosotros presentamos los de estos dos pacientes en un periodo de un año. Este tipo de tumores suelen estar enmascarados por otras patologías anorrectales.

\section{ABSTRACT}

Plasmablastic lymphoma (PBL) is a type of lymphoma with fast and aggressive growth considered a variant of nonHodgkin's lymphoma. The relative risk of developing this type of lymphoma in human immunodeficiency virus (HIV) positive patients is 80 to 110 times higher than in the general population. Lymphomas in HIV-positive patients have also been strongly associated with virus infection, which suggests an important role of those in the pathogenesis of these lymphomas. Two patients diagnosed with PBL in the anal region were identified in the medical records of the Coloproctology Service of the Hospital General México. We review the clinical course of these patients, their imaging studies and pathology reports supplemented with immunohistochemical reactions. Plasmablastic lymphoma in the anal canal is a rare disease with high mortality in the first year and a poor response to chemotherapy. There are a few cases reported in the literature. We present the ones of these two patients diagnosed the same year. These types of tumors are often masked by other anorectal disorders.

\section{INTRODUCCIÓN}

E linfoma plasmablástico (LPB) es un tipo de linfoma de crecimiento rápido y agresivo que se considera una variante del no Hodgkin; $;^{1,2}$ fue descrito por primera vez por Delecluse y sus colaboradores en 1997. El diagnóstico diferencial con otros tipos de linfomas se hace mediante inmunohistoquímica. $^{2}$

Existen tres tipos de linfoma poco frecuentes que ocurren principalmente asociados a los pacientes VIH positivos: linfoma primario asociado a derrame, LPB de la cavidad oral y LPB asociado a enfermedad difusa de Castleman. ${ }^{1,3,4}$ Este tipo de linfomas ocurren primordialmente en individuos jóvenes y son clínicamente agresivos. El riesgo relativo de desarrollar este tipo de linfomas en sujetos VIH positivos es de 80 a 110 veces mayor que en la población general y no parece tener reducción a pesar de la administración de terapia antirretroviral altamente efectiva. ${ }^{3-7}$

Los linfomas en personas VIH positivas también se han asociado fuertemente con infección por virus de Epstein Barr (EB), sarcoma de Kaposi e infección por el virus del herpes 8 , lo que sugiere un papel importante de estos virus en la patogenia de los linfomas. ${ }^{3,4,7}$ Se han reportado también casos de LPB en enfermos VIH negativos; en ellos, se observó que tienen 
una peor respuesta a la quimioterapia que los pacientes que son $\mathrm{VIH}$ positivos. ${ }^{7}$

Aunque el LPB se presenta con mayor frecuencia en la cavidad oral con invasión local, se ha informado en otros sitios tales como el estómago, los ganglios linfáticos cervicales, pulmones, órbitas, senos paranasales, colon, recto y ano. ${ }^{1,5,8}$ Decidimos realizar la publicación de estos casos, ya que la localización de este tipo de tumores en recto y ano es sumamente rara: menos del $1.5 \%$ del total de los LPB, con muy pocos casos reportados en la literatura mundial. 5,9

Histológicamente, el LPB muestra células hiperplásicas con núcleos asimétricos y desplazados del centro. ${ }^{1}$ Por inmunohistoquímica, las lesiones son negativas para CD45 y marcadores de células B (como CD20, CD19 y CD79a) y son positivas para los marcadores celulares de plasma CD38, MUM 1, CD138, BLIMP-1, XBP-1, así como un alto índice de Ki-67. ${ }^{1,2}$ Las lesiones son positivas para virus de EB hasta en el $82 \%$ de los individuos VIH positivos. ${ }^{1,2,5,7}$

\section{MATERIAL Y MÉTODOS}

\section{Selección de casos}

Se identificaron dos casos en el archivo de expedientes clínicos del Servicio de Coloproctología en el Hospital General de México con diagnóstico de LPB de la región anal, en el periodo de enero de 2014 a enero de 2015. Se realizó una revisión de la historia y evolución clínica de estos dos sujetos, se extrajeron los estudios de imagen para revisar las características de los tumores en conjunto con el Servicio de Imagenología del hospital y, así mismo, hicimos una revisión de las laminillas con el Servicio de Patología. Para el diagnóstico histopatológico de ambos casos se utilizaron bloques de parafina, que fueron teñidos con hematoxilina/eosina para observar las características celulares propias del LPB y se corroboraron con las siguientes reacciones inmunohistoquímicas: $\mathrm{CD} 20, \mathrm{CD} 3$, CD10, CD45, CD56, CD79a, Ki67, MMU-1, BLIMP-1, cadenas lambda y kappa, así como su asociación con virus de EB. Al tratarse de un reporte de caso, se realiza únicamente estadística descriptiva.

\section{REPORTE DE CASOS}

El primer enfermo fue un masculino de 42 años de edad con antecedente de $\mathrm{VIH}$ de 10 años de evolución sin tratamiento; dos meses previos a su internamiento comenzó con evacuaciones líquidas (de cinco a seis diarias) con sangrado, acompañadas de dolor anal intenso. A la exploración proctológica, se observaron condilomas perianales; al tacto rectal, se palpó una induración posterior desde el margen anal hasta aproximadamente $7 \mathrm{~cm}$. Se realizó rectosigmoidoscopia rígida, en donde se avanzó hasta $7 \mathrm{~cm}$ sin conseguir avanzar más debido a compresión extrínseca. Se llevó a cabo una resonancia magnética (RM), en donde se evidenció un tumor retrorrectal de bordes lobulados de $23 \times 10 \times 10 \mathrm{~cm}$ en sus ejes mayores, con intensidad heterogénea, con compresión extrínseca del recto desde el margen anal hasta la unión rectosigmoidea ( $F i$ guras 1 a 3). Se realizó una biopsia por punción guiada por tomografía computada (TC), con resultado histopatológico de linfoma de alto grado por clasificar; posteriormente, se practicó inmunohistoquímica utilizando 10 anticuerpos, de los cuales seis resultaron positivos, por lo que se concluyó el diagnóstico final de linfoma plasmablástico (Cuadro I).

Antes de la conclusión de la inmunohistoquímica, el paciente presentó deterioro del estado general, con elevación en el nivel de azoados y disminución de volúmenes urinarios; posteriormente, manifestó dificultad respiratoria que ameritó apoyo ventilatorio; sin embargo, tuvo falla multiorgánica con paro respiratorio y falleció.

El segundo caso fue un individuo masculino de 27 años, sin antecedentes heredofamiliares de importancia, con diagnóstico de $\mathrm{VIH}$ realizado un año antes y manejo actual por parte del Servicio de Infectología con lopinavir, ritonavir, tenofovir y emtricitabina. Inició su cuadro con aumento de volumen de la región perianal acompañado de dolor y fiebre; durante la exploración proctológica se observó un absceso perianal que fue drenado de forma ambulatoria. Tres meses después, reingresó al Servicio de Urgencias por presentar salida continua de material purulento en la región perianal, acompañada de dolor; 
a la revisión, se observó una fístula anal y una zona de fluctuación al tacto rectal, por lo que se realizó ultrasonido endorrectal. Se encontró una fístula anal abscedada, la cual recibió manejo en quirófano mediante drenaje del absceso con fistulotomía parcial más colocación de setón. Durante la exploración bajo anestesia se observó una úlcera anal, de la cual se tomó biopsia, con reporte histopatológico de neoplasia maligna de células plasmáticas

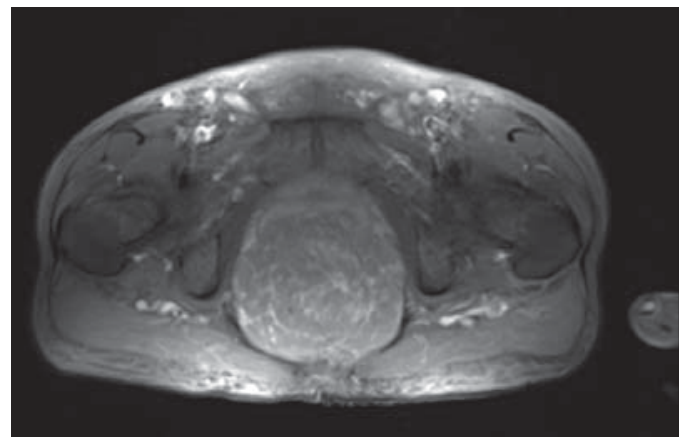

Figura 1. Se muestra un corte axial de la resonancia magnética que se realizó al primer paciente, donde se observa la tumoración linfoma plasmablástico que condiciona obstrucción total de la luz del recto.

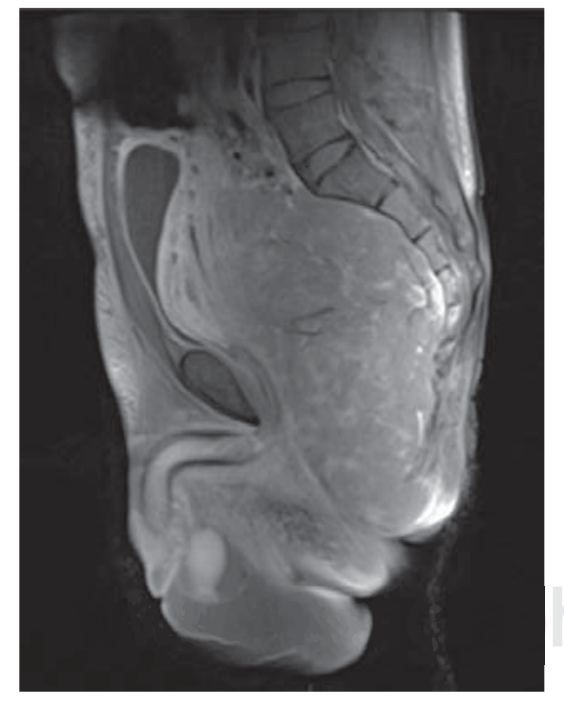

Figura 2. Corte sagital de la resonancia magnética efectuada al individuo del primer caso descrito, donde se puede ver que el tumor se extiende por arriba del promontorio sacro y causa compresión de las estructuras adyacentes anteriores.
(Figura 4A) con restricción de cadenas lambda. Se complementó con inmunohistoquímica, que fue reportada como positiva para CD79, CD138, MMU-1, positivo focal lambda y kappa (Figuras $4 B-4 D$ ). Posteriormente, se realizó una tomografía de tres regiones que evidenció conglomerados ganglionares. El

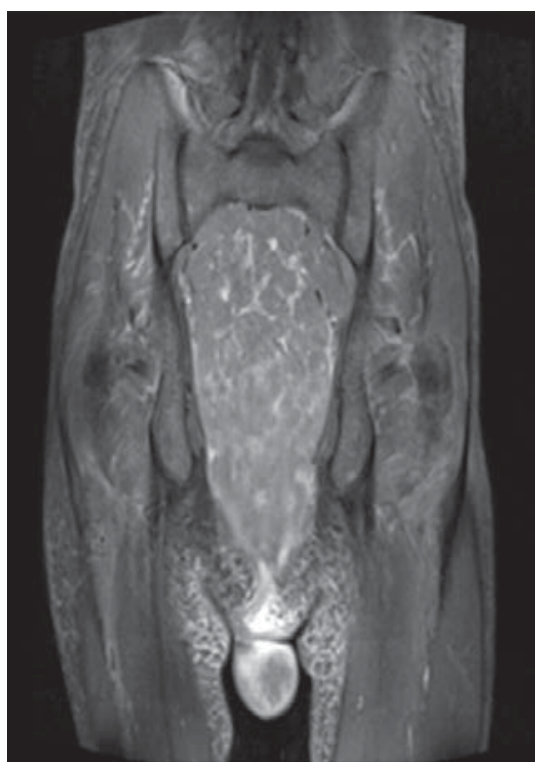

Figura 3. Corte coronal que corresponde al mismo sujeto del primer caso, donde evidenciamos la altura y extensión lateral del linfoma plasmablástico.

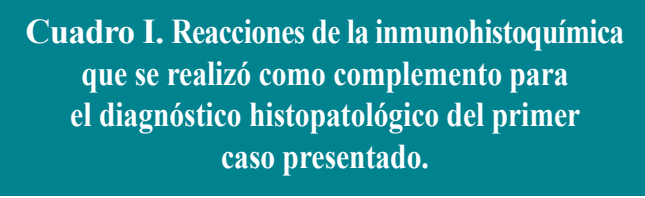

\begin{tabular}{l}
$\begin{array}{l}\text { Anticuerpos } \\
\text { empleados }\end{array} \quad$ Resultado \\
\hline
\end{tabular}

$\begin{array}{ll}\text { CD20 } & \text { Negativo cel. neoplásicas } \\ \text { CD3 } & \text { Negativo cel. neoplásicas } \\ \text { CD10 } & \text { Positivo cel. neoplásicas } \\ \text { BCL-2 } & \text { Positivo cel. neoplásicas } \\ \text { BCL-6 } & \text { Negativo cel. neoplásicas } \\ \text { CD138 } & \text { Positivo cel. neoplásicas } \\ \text { CD56 } & \text { Positivo cel. neoplásicas } \\ \text { VEB } & \text { Negativo } \\ \text { MUM-1 } & \text { Positivo cel. neoplásicas } \\ \text { Ki 67 } & \text { Positivo cel. neoplásicas 70\% }\end{array}$


sujeto evolucionó satisfactoriamente del procedimiento quirúrgico y actualmente se encuentra en manejo por parte del Servicio de Hematología. Los estudios de imagen sólo mostraron ganglios locorregionales con actividad tumoral y se descartó afección de otros órganos a distancia.

\section{DISCUSIÓN}

Los casos de linfoma plasmablástico en personas VIH negativas se han descrito después de un trasplante de órgano sólido, asociados con el tratamiento a base de esteroides para la enfermedad autoinmune y algunos otros tipos de inmunosupresión. ${ }^{2,7}$ Los principales diagnósticos diferenciales de linfoma plasmablástico incluyen al linfoma difuso de células B, plasmocitoma/mieloma, carcinoma pobremente diferenciado y melanoma. ${ }^{2,5}$
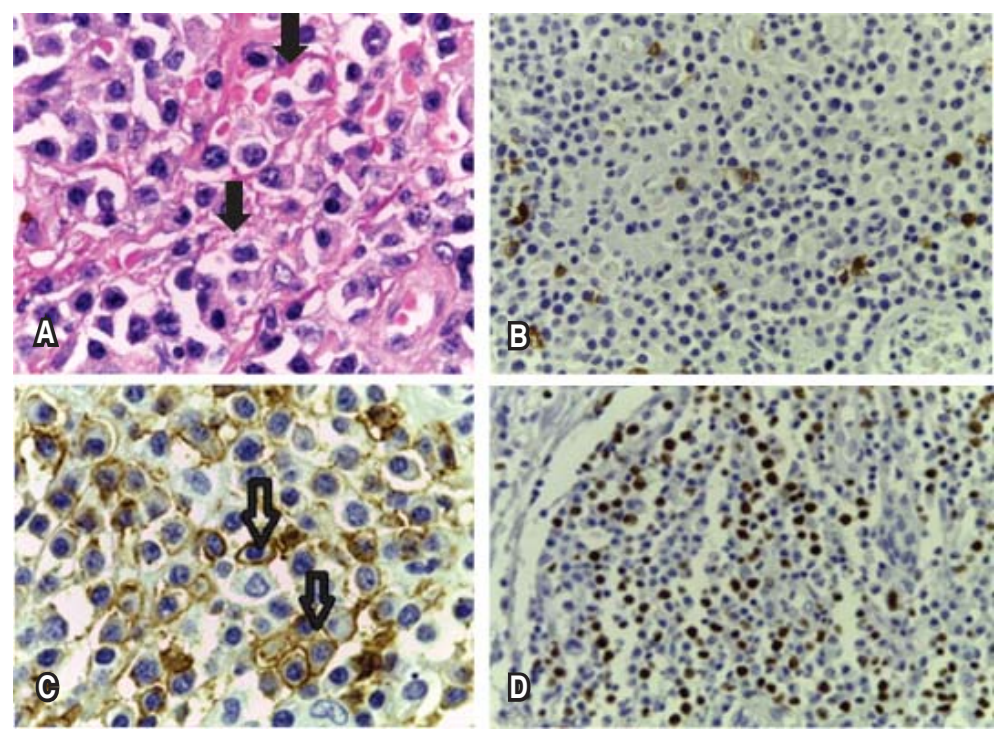

Figura 4. A. Se observa la biopsia de la lesión teñida con hematoxilina/eosina en un aumento de 100X que corresponde al segundo caso reportado, y se puede ver la morfología celular característica del LPB con células dismórficas, hiperplásicas, con núcleos irregulares y desplazados del centro. B. Corresponde a una reacción de inmunohistoquímica del mismo caso, con el marcador CD20, que se encuentra negativo. Nótese la pobre respuesta celular a este marcador, el cual generalmente es negativo en el LPB. C. Mostramos un corte de inmunohistoquímica con un aumento de 100X del mismo individuo reportado, aplicando el marcador membrana CD138, que se encuentra positivo; adviértase la hipercromía que genera en las membranas celulares del LPB. D. Corresponde al mismo caso; el marcador Ki 67 se halla con un índice de positividad mayor del 60\%.
La tomografía computada es el método de imagen más utilizado para los linfomas debido a su amplia disponibilidad y bajo costo. ${ }^{5,9} \mathrm{Sin}$ embargo, la resonancia magnética se considera el estudio de elección debido a su mejor resolución espacial, lo que permite una mejor caracterización de la infiltración a los tejidos causada por la lesión.

Las principales características morfológicas e histoquímicas del linfoma plasmablástico son la presencia de células inmaduras con abundante citoplasma, núcleo excéntrico con nucléolo prominente, la persistencia de marcadores de células de plasma tales como CD38 y CD138, y la ausencia de marcadores de células B, como CD4 y CD20. ${ }^{1}$ Además, las altas tasas de proliferación (Ki67 > 60\%) y los resultados positivos para la infección por el virus de EB ayudan en el diagnóstico; ; 1,3 sin embargo, en los dos casos presentados las reacciones para virus $\mathrm{EB}$ se encontraron negativas.

Este tipo de linfoma muestra agregados celulares cohesivos con diferenciación morfológica variable, desde inmunoblastos hasta las características células plasmáticas más maduras. ${ }^{1}$ La actividad mitótica suele ser rápida y se encuentran con frecuencia cuerpos apoptóticos. Las células tumorales también son no reactivas para el BCL6 marcador central germinal. ${ }^{1}$

Los pacientes VIH positivos y negativos con linfoma plasmablástico exhiben diferentes características clinicopatológicas, incluyendo una respuesta más favorable a la quimioterapia y la supervivencia en los individuos VIH positivos. Los sujetos VIH negativos tuvieron una mediana de supervivencia global de nueve meses, contra 14 en personas VIH positivas. $3,4,7$

El pronóstico para los enfermos con linfoma plasmablástico es pobre; la mayoría de ellos mueren dentro del primer año después del diagnóstico. ${ }^{7,10}$

La quimioterapia con combinación CHOP (ciclofosfamida, doxorrubicina, vincristina y prednisona) ha sido el régimen terapéutico más comúnmente utilizado. Sin embargo, dado el alto índice de proliferación del linfoma plasmablástico y su comportamiento agresivo, la combinación más agresiva con regímenes como CODOX-M/IVAC (ciclofosfamida, vincristina, doxorrubicina, metotrexato, ácido folínico) también puede ser utilizada. Los estudios 
actuales están enfocados en investigar más a fondo los mecanismos patogénicos y factores pronósticos de esta variante de linfoma asociada al $\mathrm{VIH}$, poco frecuente y agresiva..$^{4,7}$

\section{CONCLUSIÓN}

El LPB en el canal anal es una patología poco frecuente, con una mortalidad elevada dentro del primer año y una pobre respuesta al tratamiento con quimioterapia. ${ }^{5,9}$ Existen pocos casos reportados en la literatura mundial; nosotros presentamos los de estos dos pacientes en un periodo de un año, lo cual es debido al alto número de individuos que son atendidos en este centro hospitalario. Este tipo de tumores suelen estar enmascarados por abscesos y fístulas recurrentes, por lo que ante cuadros similares, sobre todo en sujetos inmunocomprometidos, se debe sospechar esta patología y realizar toma de biopsias de forma temprana. ${ }^{10}$

\section{REFERENCIAS}

1. Bautista-Quach MA, Ake CD, Chen M, Wang J. Gastrointestinal lymphomas: Morphology, immunophenotype and molecular features. J Gastrointest Oncol. 2012; 3: 209-225. doi:10.3978/j.issn.20786891.2012.024.

2. Mansoor M, Alani FS, Aslam MB, Kumar SN, Sahasrabudhe N, Khan D. A case report of cecal plasmablastic lymphoma in a HIV negative patient. Eur J Gastroenterol Hepatol. 2012; 24: 332-335.

3. Dong HY, Scadden DT, de Leval L, Tang Z, Isaacson PG, Harris NL. Plasmablastic lymphoma in HIV-positive patients: an aggressive Epstein-Barr virus-associated extramedullary plasmacytic neoplasm. Am J Surg Pathol. 2005; 29: 1633-1641.

4. Schommers P, Wyen C, Hentrich M, Gillor D, Zoufaly A, Jensen B et al. Poor outcome of HIV-infected patients with plasmablastic lymphoma: results from the German AIDS-related lymphoma cohort study. AIDS. 2013; 27: 842-845.

5. Brahmania M, Sylwesterowic T, Leitch H. Plasmablastic lymphoma in the ano-rectal junction presenting in an immunocompetent man: a case report. J Med Case Rep. 2011; 5: 168. doi: 10.1186/1752-1947-5-168.

6. His ED, Lorsbach RB, Fend F, Dogan A. Plasmablastic lymphoma and related disorders. American Society for Clinica Pathology. Am J Clin Pathol. 2011; 136: 183-194.

7. Corti M, De Carolis L, Campitelli A, Narbaitz M, Baré P. Response of human immunodeficiency virus associated oral plasmablastic lymphoma to highly active antiretroviral therapy without chemotherapy: case report and literatre review. Infect Dis Clin Pract. 2012; 20: 79-81.

8. Koike M, Masuda A, Ichikawa K, Shigemitu A, Komatus N. Plasmablastic lasmablastic lymphoma of the duodenal and jejunum. Int J Clin Exp Pathol. 2014; 7: 4479-4483.

9. Lim JH, Lee $M H$, Lee MJ, Kim CS, Lee JS, Choi SJ et al. Plasmablastic lymphoma in the anal canal. Cancer Res Treat. 2009; 41: 182-185. doi:10.4143/ crt.2009.41.3.182.

10. Rapose A, Naniwadekar A. Plasmablastic lymphoma masquerading as perineal abscess in a homosexual man. Infect Dis Clin Pract. 2009; 17: 274-275.

Correspondencia:

Cristina Grijalva Santana

Centro Médico ABC, campus Observatorio. Sur 136 Núm.116, Consultorio 216,

Col. Las Américas, 01120, Ciudad de México.

E-mail: ccosmer@yahoo.com.mx 